\title{
Burnout entre médicos da Saúde da Família: os desafios da transformação do trabalho
}

\author{
Burnout among Family Healthcare physicians: \\ the challenge of transformation in the workplace
}

Katia Virginia de Oliveira Feliciano ${ }^{1}$

M aria Helena Kovacs ${ }^{2}$

Sílvia Wanick Sarinho ${ }^{2}$

${ }^{1}$ Instituto $M$ aterno Infantil de M edicina Integral Prof. Fernando Figueira. Rua dos Coelhos 300, Boa Vista. 50070-550 Recife PE. kvofeliciano@gmail.com ${ }^{2}$ Faculdade deCiências M édicas, Universidade de Pernambuco.
Abstract Thescope of this paper is to understand how conflicts with the institution and disagreements regarding team members' attributions are interpreted by Family $\mathrm{H}$ ealthcare physicians from the burnout perspective. Qualitative research was conducted with 24 doctors in Recife between August 2005 and N ovember 2006 based on management evaluation (geographic access, conflicts within the team, between teams and the District, be tween the team and the community and public violence in the area), and four teams were selected in each of the six Health Districts. Semi-structured interviews were then conducted. An enormous discrepancy between the expectations of physicians and the reality of the workplace was detected. They reject the institutional consultation priority and demands for productivity. They suffer from what they consider loss of professional identity, with nurses attributions questioning the historic essence of their practice. There is discredit concerning change and a desire to abandon the profession, especially amongst those with the highest expectations concerning conversion of themodel. A broad set of elements was detected that favor simultaneous exhaustion and professional inefficiency and provoke negative attitudes, stressing the need for promoting health in the workplace. Key words Burnout, O ccupational fatigue, Primary Care Physicians, Family Healthcare
Resumo Compreender como os conflitos com a instituição e desacordos quanto às atribuições de membros da equipe, são apreendidos e reconstruídos pelos médicos da Saúde da Família, sob a perspectiva do "burnout". M étodos: Pesquisa qualitativa desenvolvida no Recife, entre agosto de 2005 e novembro de 2006, com 24 médicos. Foram selecionadas quatro equipes a partir de avaliação da gerência (acesso geográfico, conflitos na equipe, entre equipe e Distrito, entre equipe e comunidade violência pública na área), em cada um dosseis Distritos Sanitários. Foram realizadas entrevistas semiestruturadas. Resultados: Osmédicos revelam enorme discrepância entre expectativas e realidade do trabalho. Rejeitam a priorização institucional da consulta ecobrança deprodutividade. Sofrem diantedo queconsideram à perda da identidadeprofissional: atribuições da enfermeira questionam o núcleo histórico da sua prática - o diagnóstico e o tratamento da doença. Sobretudo entre aqueles com maiores expectativas na conversão do modelo, existe descrédito quanto às mudanças e há o desejo de desistir. Observa-se amplo conjunto de elementos quefavorecem o desenvolvimento simultâneo deesgotamento eineficácia profissional, eque provocam atitudesnegativas, reforçando a necessidadeda promoção da saúde no trabalho.

Palavras-chave Burnout, D esgaste ocupacional, M édicos de Cuidados Primários, Saúde da Família 
Introdução

O s médicos da Estratégia Saúde da Família (ESF) estão sob a pressão da disparidade de saberes, práticas eresponsabilidades. A atuação hegemônica focal iza-sena assistência médica especial izada ${ }^{1,2}$. Na ESF o médico deve: a) ser preferencialmente um generalista que aten da todos os membros da família e integre as necessidades individuais de saúde às ações coletivas; b) assumir a co-responsabilidade sanitária pela área adscrita, atuando inclusive sobre os condicionantes da saúde e da doença; e c) planejar e monitorar as ações e os resultados. A grande expectativa institucional quanto à aceitabilidade eà legitimidade da ESF, mediante a participação social, implica ainda no desenvolvimento de habilidades para a ação política ${ }^{3}$.

O conhecimento e o saber-fazer, segundo Batista e Codo ${ }^{4}$, são el ementos estruturais da identidade do trabal hador, constituindo-se como a base daquilo que Ihe será exigido socialmente: a competência profissional. Para Ciampa 5 , a identidade manifesta as condições existentes para se tornar um ser concreto, parte de uma complexa rede material, simbólica e imaginária on de o contínuo processo de identificação implica o ter-sido, o estar-sendo e o vir-a-ser. É justamente a relação dialética entre inovação e sedimentação que, na visão de Ricoeur ${ }^{6}$, problematiza a busca de permanência no tempo, revelando o confronto entre mesmidade (o mesmo) eipseidade (pelo mesmo).

$\mathrm{N}$ a mesmidade, a ideia de permanência associada à identidade podeser reconhecida pelo conjunto de valores, normas e ideais com que uma pessoa, ou uma coletividade, se reconhece eéreconhecida. No caso dos médicos, convém recordar a autonomia no seu processo de trabalho ea tradicional hegemonia nas equipes de saúde, 0 quetorna mais crítica a integração da assistência médica ao trabalho coletivo ${ }^{2,7}$. Muito embora, parte da contínua reconstrução da identidade profissional possa ser apreendida na progressiva vinculação direta da organização da assistência às políticas públicas.

A normatização de condutas e procedimentos, imprescindíveis para articular o trabal ho médico à dinâmica programática, e as obrigações produtivas que submetem esse trabalho a crescente controle institucional, levam à percepção de liberdade profissional diminuída ${ }^{2,8}$. Contudo, a permanência do núcleo central da prática médica remete à reflexão de Ricoeur ${ }^{6}$ sobre 0 componente estável da identidade. N essas circunstâncias, as mudanças do trabalho médico foram fracas e ameaçaram a semelhança sem destruí-la, com o novo entrando na composição do antigo.

O trabal ho na ESF abre uma perspectiva de renovação que tensiona a dimensão identitária. Hoje, cada profissional é forçado a olhar e a ver no outro uma nova face, bem como a olhar-se e ver-se a si mesmo com uma nova face. A integralidade da atenção pressupõe a reciprocidade entre intervenções técnicas e interação da equipe, exigindo grandes transformações na prática mé dica (conteúdos das tarefas, normas e padrões, atribuição de competências, integração de atividades e relações hierárquicas e interpessoais). Transformações que envolvem a negociação entre os sentidos e os valores das categorias profissionais, da instituição e da população, o que requer cuidado redobrado com as condições de trabalho $0^{9,10}$.

É nesse percurso produtor de possibilidades novas no pensar eno fazer do médico quese constitui o que Ricoeur ${ }^{6}$ designa de identidade por ipseidade, traduzindo um pólo de inovação, o qual supõe a noção de uma categoria profissional que vai se descobrindo na vivência do tempo. As implicações conceituais e práticas desse processo reconstrutivo, sobretudo em situações onde as limitações na comunicação e as deficiências do suporte organizacional favorecem a busca de soluções pessoais para as tensões e os embates do trabalho, podem levar à baixa realização profissional e ao esgotamento ${ }^{4,11,12}$. Fatores centrais para o surgimento dos sentimentos e atitudes negativas no trabal ho que caracterizam o burnout $9,10,13$.

A retomada do tema da identidade profissional do médico sob a perspectiva do burnout advém, ainda, das pesquisas que encontraram uma clara relação entre a crise identitária e essa síndrome. No Brasil, Batista e Codo ${ }^{4}$ constataram que o sofrimento gerado pela perda da identidade profissional e pela discrepância entre a imagem criada e o lugar que atualmente ocupa o professor afeta a prevalência do burnout. A distribuição mundial do burnout em equipes de atenção primária resultante, principalmente, de mudanças no processo e conteúdo do trabalho e do temor do imprevisível no cotidiano dos serviços $^{11,12}$, outrossim evidencia a tensão ocasionada pela necessidade de manifestar outros predicados na identidade profissional.

Tamayo e Tróccoli ${ }^{10}$ mostraram que Freudenberger e M aslach, partindo de vivências distintas, utilizaram o termo burnout para definir uma síndrome psicológica, advinda da sobrecarga emocional crônica originada pela experiência 
individual negativa nas relações interpessoais com usuários, que provoca negativismo e desinteresse em profissionais antes motivados e comprometidos. A ênfase nos contextos de trabalho surgiu após o reconhecimento do caráter paliativo de intervenções sobre o comportamento individual. I dentificaram-se condicionantes organizacionais do burnout (sobrecarga, limitações e ambiguidade no desempenho de papéis, conflitos interpessoais, falta de controle sobre o trabaIho, conflitos de valores, etc. $)^{10,13-15}$.

Farber ${ }^{16}$ conceituou o burnout como uma síndrome do trabalho oriunda da discrepância percebida entre esforço e consequência, influenciada por aspectos pessoais, organizacionais e sociais. Codo eVasques-M enezes ${ }^{9}$ afirmaram que a acentuação do conflito entre a exigência de um trabaIho qual ificado eas possibilidades reais de sua execução tem elevado a frequência do burnout, cuja compreensão solicita uma aproximação às interrelações entrea singularidade das pessoas, a situação de trabalho e o contexto de vida. Essa síndrome acomete aqueles que trabal ham sob condições precárias, a parte da atividade desempenhada.

$O$ conceito de referência aindaé 0 de $M$ aslach ejackson que definem o burnout como um processo sequencial que envolve exaustão emocional (perda ou desgaste dos recursos emocionais), despersonalização (sentimentos e atitudes negativas no trabal ho) ebaixa realização pessoal (sentimentos deinadequação efracasso). Esta definição originou o M BI - M aslach Burnout Inventory ${ }^{10}$ - 0 instrumento mais utilizado para avaliar a ocorrência dessa síndrome. No Brasil, o MBI foi adaptado e tem sido aplicado junto às distintas categorias profissionais9. A pesar das diferenças entre autores acerca dos model os explicativos e da sequência de aparecimento esignificado, os três componentes acima descritos são centrais no burnout.

O burnout mantém uma relação estreita com a percepção de suporte organizacional, demonstrando a importância da mediação institucional para a saúde e o bem-estar no trabalho ${ }^{13-15}$. No Brasil, pesquisa de Tamayo e Tróccoli ${ }^{13}$ revelou que sobrecarga, ascensão e salários, gestão de desempenho e suporte social são preditores significativos da exaustão emocional: um fator central do burnout. Entre profissionais de saúde atuantes em hospitais públicos, Oliveira et al. ${ }^{14}$ encontraram correlação negativa alta entreestilo de gestão da chefia e exaustão emocional, bem como correlação positiva significativa entre sobrecarga no trabalho e as dimensões desumanização e decepção. A sobrecarga estava relaciona- da à baixa realização no trabalho e ao distanciamento contraproducente.

Os estudos sobre o burnout privilegiam 0 método quantitativo e os enfoques centrados na informação sobre os riscos e na responsabilidade individual. Este artigo é parte de pesquisa na qual se utilizou o método qualitativo para, considerando os desafios da transformação do trabalho, desenvolver uma reflexão preliminar sobre as condições para ocorrência do burnout na ESF. Nele, a partir das percepções e interpretações dos médicos sobre o trabalho cotidiano, buscou-se explorar como os conflitos com a instituição e os desacordos quanto às atribuições são apreendidos e reconstruídos por esses profissionais. Estecaminho foi esboçado em investigação realizada com professores no Brasil ${ }^{9}$.

\section{Métodos}

Realizou-se estudo qualitativo baseado em depoimentos de profissionais que atuam na ESF, na cidade do Recife, entre agosto de 2005 e novembro de 2006, utilizando abordagem hermenêutica-dialética ${ }^{17,18} .0$ projeto foi aprovado pelo ComitêdeÉtica em Pesquisa do Instituto M aterno Infantil Prof. Fernando Figueira (IMIP). N este artigo, estão sendo apresentados os resultados relativos aos médicos.

Para a escolha das equipes, os gerentes dos seis Distritos Sanitários do Recife, apoiados por seu grupo técnico, fizeram um julgamento mediante uma escala ordinal que indicava, para cada item, um grau de intensidade decrescente. Nos itens sobre a existência de conflitos na equipe, entreequipee Distrito, entre equipeecomunidade e de violência pública na área, as respostas foram codificadas nas categorias: sempre, às vezes, raramente e nunca. Para a pergunta sobre dificuldade no acesso geográfico, as respostas foram: muita, pouca, nenhuma.

A partir da soma dos valores correspondentes aositens, cada equipefoi classificada em situação boa, regular, ruim e péssima. Quando duas ou mais equipes totalizaram o mesmo número de pontos, deu-se prioridade àquela que apresentava mais conflitos internos. Quando o mesmo número de pontos correspondia a pontuações iguais nos itens avaliados, fez-se sorteio utilizando uma tabela de números al eatórios. Sele cionaram-se 24 equipes com mais de um ano de atuação (quatro boas, sete regulares, sete ruins e seis péssimas). Em dois dos Distritos, nenhuma equipe foi classificada como boa, assim, para 
aproximar-seao perfil do Distrito, incluiu-semais um representante da classe predominante. A preocupação foi focalizar a maior diversidade possível de situações práticas que poderiam influenciar as percepções dos profissionais sobre os contextos de trabalho.

Em todas as unidades de saúde, onde atuavam as equipes selecionadas, foi feita observação, em curto espaço de tempo, para estabelecer um contato, ainda que superficial, com o ambiente de trabalho. As entrevistas foram efetuadas por duas pesquisadoras, em salas cedidas ou indicadas pelos Distritos, visando garantir o sigilo das informações e propiciar condições para a reflexão suscitada pelo roteiro, do qual constou: trajetória profissional, expectativas e relevância do trabalho, papel do profissional, organização e processo de trabalho, relações na equipe, da equipe com o Distrito Sanitário ecom a comunidade, sentimentos sobre as práticas, morbidade referida ao trabalho e qualidade de vida.

As entrevistas foram gravadas e transcritas na íntegra. A pós cada sessão o material produzido foi avaliado, sendo necessárias no mínimo duas sessões para explorar o roteiro. Na etapa de organização das informações, cada equipe recebeu um código numérico e cada um de seus integrantes entrevistados foi identificado pela categoria profissional eo código atribuído à equipe, garantindo 0 anonimato. Este código está sendo utilizado nas citações ilustrativas extraídas das entrevistas apresentadas nos resultados. No destaque dado às citações buscou-se compreender o sentido próprio da citação na totalidade do pensamento do qual foi separada ${ }^{1}$.

Procedeu-se a uma leitura minuciosa e repetida de cada entrevista para identificar as ideias, processos de racionalização e sentimentos por meio dos quais os profissionais expressam suas vivências e percepções da prática cotidiana. Delinearam-se as principais semelhanças e diferenças entre entrevistas. 0 trabalho de três pesquisadoras ampliou a visão sobre a lógica interna do grupo ${ }^{19}$. Neste artigo, as reflexões focalizam três áreas temáticas desenvolvidas pelos próprios participantes: (a) discrepância entre valores institucionais e desejos individuais; (b) desacordos quanto às atribuições dos integrantes da equipe e (c) consequências negativas do trabal ho.

\section{Resultados ediscussão}

Dos 24 médicos entrevistados, dois terços são mulheres. M etadeépediatra, oito clínicos, sendo os demais: psiquiatra, infectologista, tocogine cologista e anestesiologista. Com mediana do tempo de formado de 22 anos (amplitude entre dois e 50 anos), cinco são aposentados e 10 têm vínculo empregatício com outro serviço público, sendo oito como plantonistas. Eles construíram suas trajetórias profissionais em hospitais e clínicas ambulatoriais. Poucos haviam lidado com as mudanças do trabalho nos centros de saúde para ampliar o acesso às ações de vigilância à saúde, desenvolvendo um enfoque preventivo quecontinuava, conforme Stotz ${ }^{20}$, tendo os diagnósticos como o ponto de partida para abordagem dos problemas.

Participantes de diferentes configurações da atenção à saúde, os médicos entrevistados têm 4 anos e 5 meses como mediana do tempo de trabalho na ESF (distribuiç̧ão entre três meses e 10 anos). M etade iniciou o trabal ho nesse modelo assistencial noutros municípios. A inserção na ESF deveu-se ao desejo de abandonar os plantões, mas era marcante 0 interesse em trabalhar mais próximo à comunidade. M encionam também a remuneração diferenciada, o fato de representar uma primeira oportunidade para re cém-formados e a perspectiva de continuidade do trabalho após a aposentadoria, bem como a aceitação do convite institucional de adesão. No período de realização das entrevistas, 19 estão submetidos a regime de contrato temporário.

\section{Discrepância entre os val ores institucionais eos desejos individuais}

Quase sempre, ao ingressar na ESF, os médicos desejavam ampliar o seu campo de competência e responsabilidade, conferindo novos sentidos aos papéis a serem desempenhados na equipe local. Eles continuam aspirando uma prática que integre o diagnóstico e o tratamento de doenças às dimensões preventivas e promocionais da saúde. Prática ondeadquirerel evância o componente educativo demarcatório da diferença, do ponto de vista do exercício da medicina (e do trabalho da equipe), entre a atenção tradicional e a ESF. Contudo, para uma vertente, a especificidade do trabalho decorre da real ização deatividades educativas em grupo, associadas à promoção da saúde. Para outra, resulta do aumento do tempo requerido na atenção individual para a conversa com os pacientes e seus familiares.

A diversidade de contextos possibilita desdobramentos distintos na reorientação da atenção básica. No Recife, visando responder à pressão 
da demanda, a instituição decidiu aumentar os turnos destinados à consulta médica e realizar 16 consultas por turno. Com mediana do tempo na equipeatual deum ano ecinco meses (amplitude entre três meses e 4 anose 5 meses), numa semana típica de trabalho, esses médicos dedicam de seis a oito turnos às consultas; de um a três turnos às visitas domiciliares e às atividades educativas grupais, restando um turno para as reuniões administrativas. A agenda não contempla a interlocução com as redes sociais locais, nem com outros setores de atividade. A insatisfação está expressa neste comentário:

[...] você se sente sufocado, consulta, receita, exame para solicitar; então tem aquela carga de paciente que você normalmente atende, mas você nunca consegue cumprir aquilo, sempre tem um encaixe, sempre tem mais paciente do que o que você deveria ver, então, é cansativo, termina sobrecarregando. (M édico3 - 34 anos, 10 anos de formado, 10 anos na ESF, 4 anos e 9 meses na equipe atual).

A discrepância da percepção entre o esforço feito e os resultados obtidos é referida em todas as entrevistas, sendo diretamente associada à decisão institucional de responder às demandas individuais, num contexto de priorização pelas comunidades da atenção curativa e de necessidades de consultas reprimidas desde antes da atuação da equipe. Aspectos que, para esses profissionais, afetam o trabalho médico demodo ainda mais negativo devido ao grande número de famílias.

O excesso de demanda dá maior visibilidade às limitações do suporte organizacional (infraestrutura física e material, medicamentos, exames rotineiros, qualificação e interação da equipe, sistemas de referência e contra-referência), reforçando a percepção de que os problemas são maiores do que os recursos disponíveis para re solvêlos. 0 desacordo percebido produz um sentimento de baixa realização profissional, já que todo o esforço volta-se para uma forma de atuação distanciada do que reconhecem como sendo a missão da ESF. É corriqueiro o sentimento de perda, traduzindo a privação de algo a que têm direito.

A pesar das necessidades de consultas insatisfeitas, entre os médicos que enfatizam a prática educativa coletiva, émarcante a compreensão de queo recurso à clínica para regular o exercício da medicina é um erro estratégico, um retrocesso no modo operatório proposto, algo que dificulta o seu êxito. Este depoimento ilustra o sentimento de perda:
[...] se o PSF trabalha não só a medicina curativa, mas também a preventiva, então, tinha que ter horário pras visitas, pras pal estras e na realidade no cronograma colocaram $80 \%$ de atendimento. Como é que pode? $\mathrm{N}$ ão, é porque existe uma demanda reprimida - essas pessoas foram acostumadas a ter o posto - e continua como uma medicina só curativa. [...] se éPSF, por que está igual a um posto convencional? (M édical - 44 anos, 20 anos de formada, 5 anos na ESF, 3 anos na equipe atual).

Os profissionais que ressaltam a dimensão educativa da consulta concentram suas críticas na cobrança de produtividade, aspecto rejeitado por quase todos os entrevistados. Eles sentem-se impotentes e frustrados diante de um processo de regulação do desempenho do médico que, segundo opinam, cria obstáculos para a implantação da ESF. Esta médica expressa a insatisfação:

[...] o numero de pacientes eo pouco tempo pra consulta, então eu não tenho condições, não tem a menor possibilidade, porque assim eu vou deixar de fazer PSF, eu vou fazer um posto tradicional, que o médico antigamente olhava para o paciente passava o remédio e mandava embora. ( $M$ édica23 - 52 anos, 27 anos de formada, 4 anos e 6 meses na ESF e um ano na equipe atual).

A representação pelos médicos do componente educativo como demarcatório dos modelos de atenção, não abrange o horizonte de práticas previstas pelo M inistério da Saúde³. Práticas de saúde capazes de traduzir a responsabilidade sanitária e de estabelecer parcerias em prol da qualidade de vida. Esta afirmação não pretende minimizar o significado do sofrimento desses profissionais em suas tentativas de adequação aos contextos de trabalho. Tampouco encobrir as possíveis consequências da ambiguidade institucional na efetuação dos princípios políticos gerais e das normas na prestação direta de serviços.

No Brasil, estudos encontraram que a frequência do burnout em profissionais de saúde é diretamente proporcional a percepção de diferenças entre os níveis reais e idealizados de valores organizacionais $s^{15,21,22}$. 0 sentimento de perda advindo do descompasso entre o que é desejado eo queé, defato, valorizado pela instituição leva à baixa realização profissional e ao desgaste persistente $^{4,9,10}$, semelhante ao relatado nesta pesquisa. Premidos pelas incertezas sobre o futuro da ESF e os seus próprios futuros, sobretudo os médicos com maiores expectativas acerca da educação em saúde, confessam o desejo, presenteou já superado, de abandonar o trabalho. Este desabafo reflete esse anseio: 
[...] o PSF descaracterizado, é uma das coisas que está meangustiando muito de unsanos pra cá, porque o PSF deixou de fazer o trabalho de educação. [...] eu passei por uma crise de identidade, eu não estou satisfeita com meu trabalho, se eu vou continuar assim, eternamente insatisfeita, então eu vou ter quesair. Eu acho isso conflituoso, muito desgastante, você quer fazer, mas não pode, não é aquilo de verdade que acontece. Eu cheguei a pensar no final do ano passado em sair do PSF, a equipe fez que eu desistisse de desistir. (M édica4 - 31 anos, 6 anos de formada, 4 anos e 7 meses na ESF e 1 ano e 7 meses na equipe atual).

A desistência éuma estratégia pessoal de enfrentamento da baixa realização profissional e do esgotamento, tradutora do descrédito de que ocorram mudanças institucionais em curto prazo. Codo e Vasques-M enezes ${ }^{9}$ destacaram o caráter intermitente, sorrateiro e multifacetado da desistência, a qual se assemelha a um monstro de mil cabeças: quando uma écortada outra toma o seu lugar.

\section{Desacordos quanto às atribuições} dos integrantes da equipe

A percepção da própria falta de identificação com a tarefa e da falta de competência técnica de membros da equipe, acentuam a insegurança sobre o desempenho de papéis. A significativa presença de pediatras entre os entrevistados talvez explique a falta de identificação com a tarefa que resulta numa relação conflituosa com o trabalho prescrito para ser executado na atenção à mulher, principalmente no cuidado pré-natal, a qual torna manifesta a incerteza entre as exigências das práticas e os conhecimentos e habilidades requeridos para concretizá-las.

Para enfrentar os sentimentos de fracasso diante do pré-natal, alguns médicos adotam como estratégia o distanciamento da situação e se negam a dar assistência à gestante, orientando o encaminhamento de casos passíveis de resolução no nível local. Para O nocko Campos²3 quando a insegurança técnica é grande não é possível discernir sobre os riscos. Assim, na busca por aplacar a angústia, tudo acaba sendo banalizado, caracterizando uma das formas da burocratização. Eis um exemplo:

0 prénatal eu não quero de jeito nenhum, pré natal não é minha praia, eu não quero atender gestante... N ão gosto! Não gosto não! Eu não sei, eu não sei conduzir gestante. (M édica5 - 46 anos, 24 anos de formada, 4 anos na ESF e 9 meses na equipe atual).
A pressão contínua da demanda reprimida sobre a equipe, em particular sobre os agentes, exacerba a crítica sobre a falta de competência técnica dos agentes comunitários para marcação de consultas. A garantia da oportunidade de acesso ao atendimento daqueles que realmente necessitam é uma preocupação constante dos médicos. São comuns as discordâncias quanto aos critérios adotados pelos agentes na definição de prioridades para agendamento e os atritos resultantes de interferências consideradas indevidas e da falta de confiança (alguns suspeitam da concessão de acesso privilegiado). Em algumas equipes a enfermeira faz a mediação da relação entre 0 médico e os agentes. $\mathrm{Na}$ visão dos médicos, a prática clínica está sujeita ao controle dos agentes. Este depoimento éilustrativo:

[...] eu não sei como é o critério para selecionar esses pacientes e eu fico insegura, será que eu estou atendendo todos que deveria, será que não teria casos mais graves que eu poderia está atendendo? Essa triagem inicial já éfeita pelas ACS, eu acho que a gente fica meio que na mão, entre aspas, delas, meu trabalho está intimamenterelacionado ao trabalho delas. [...] eu passei, vi uma senhora extremamenteanêmica, vi uma ictérica, que não estava sendo acompanhada... ( M édica13 - 40 anos, 17 anos de formada, 6 meses na ESF e na equipe atual).

Por outro lado, os médicos criticam o que consideram a falta de competência técnica da enfermeira para consultar e prescrever medicamentos, trazendo à tona o conflito e a ambiguidade de papéis. Quando entraram na ESF, alguns se sentiram chocados pela abrangência das atribuições e pelo poder quea enfermeira detém na equipe. Atualmente, segundo afirmam, já conseguem lidar melhor com essa realidade. Existeuma enorme insatisfação. Em geral, suportam a situação, mas é raro realmente aceitá-la. Em casos extremos, chegam a se sentir sem espaço para o exercício da medicina.

A inserção na ESF origina transformações profundas na capacidade de autogestão do trabalho, no saber operante e na histórica hegemonia dos médicos nas equipes de saúde, o que pode afetar negativamente a sua auto- estima ${ }^{7}$. Pesquisa mostrou que o médico não parece disposto a perder a sua hegemonia na equipe ${ }^{24}$. 0 fato da consulta de enfermagem não ser uma ação complementar ao ato médico, questiona a pretensão de validade do direito exclusivo dos médicos ao conjunto de saberes e responsabilidades que demarcam o núcleo histórico da sua prática: o diagnóstico e o tratamento da doença. As opiniões 
sobre a competência técnica da enfermeira estão impregnadas pelo sentimento de perda em relação à identidade profissional. Esta constatação 0 atesta:

[...] foi um choque pra mim, porquena formação da gente não existia a enfermeira com tanto poder como ela tem hoje na unidade de saúde da família, foi um choque muito grande quando eu cheguei, porque a enfermeira, ela fazia puericultura, fazia prevenção, eu nunca tinha visto isso. Eu não fui preparada para ir pra um PSF, eu fui preparada para ser pediatra - derepente eu chego e vejo a enfermeira sendo médico, eu fiquei horrorizada, ai me perguntei: o que éque eu estou fazendo aqui, o quêsobrou pra mim? (M édica23 - 52 anos, 27 anos de formada, 4 anos e 6 meses na ESF e um ano na equipe atual).

Há duas décadas a consulta de enfermagem é uma atribuição legal mente prevista ( Lei $n^{\circ} 7.498$ / 86 do Consel ho Federal deEnfermagem; Decreto 94.406/87 do M inistério da Saúde), mas éa partir da expansão daESF, em especial nos grandes centros urbanos, que adquire rel evância social. Representa um fato novo na ordem das coisas no trabal ho médico, que provoca mudanças de difícil aceitação. Mudanças que suscitam conflitos entre colegas e dificultam a integração das ações. Eis um exemplo:

A minha maior dificuldadeéo meu relacionamento com a enfermeira, ela prescreve medicação sem ser médica, eu já conversei com ela, ela não aceita, tenho até medo porque no dia quea bomba estourar vai ser na minha equipe, certo? A semana passada eu mostrei pra ela queaquilo era uma prescrição de médico, que eu podia denunciar até no Conselho e não fiz. [...] ela guardou o prontuário com medo que eu mostrasse a prova do que ela tinha prescrito. (M édical1 - 50 anos, 26 anos de formada, 9 anos na ESF e 1 ano e 4 meses na equipe atual).

Segundo Peduzzi ${ }^{25}$, a integração das ações e a interação comunicativa dos membros da equipe requerem o reconhecimento das diferen çastécnicas entre os trabalhos especializados, o questionamento das desigual dades estabelecidas entreos distintos trabal hos e a aceitação da interdependência da autonomia profissional. Os mecanismos de definição e de distribuição das atribuições na ESF problematizam o monopólio sobre o saber e a prática médica, significando uma ruptura com o conjunto interiorizado de referências nas quais os médicos se reconhecem e são reconhecidos $^{1,2,7,24}$. Vejamos a opinião desta médica:

Eu acho que prescrição de medicamento deveria ficar a critério médico, ela (a enfermeira) pode dar uma orientação - está com tosse, vamos fazer um lambedor - ela pode, sem sombra de dúvida, dar uma orientação de tratamento não medicamentoso. A gora, a responsabilidade demedicamento, até porque a gente sabe que tem as interações medicamentosas, tem os efeitos colaterais, tem uma série de coisas, isso deveria ficar a critério do mé dico. (M édica13 - 40 anos, 17 anos de formada, 6 meses na ESF e na equipe atual).

Para Schrai ber ${ }^{1}$ a preservação da autonomia técnica significa para o médico uma estratégia essencial para controlar o processo de trabalho. Nesse sentido, ao longo da transformação do trabal ho médico, a continuidade da estrutura o núcleo técnico da prática resguardado no plano das representações - vinha permitindo que, diante das dificuldades, esses profissionais buscassem formas conciliatórias para reproduzir 0 tradicional. $\mathrm{Na}$ ESF, a descontinuidade dessa estrutura pode ser percebida como desprestígio e desvalorização social da sua autoridade técnica, reiterando a importância do diálogo para a aprendizagem individual e coletiva de habilidades novas de interação e reflexão.

\section{Consequências negativas do trabalho}

As limitações da comunicação na equipe que fragilizam as negociações sobreas formas de atuar, na visão dos médicos, são alimentadas pelo apoio institucional insuficiente. Para reduzir os efeitos do desgaste crônico, el es conversam com amigos efamiliares, recorrem à religião, deitam para relaxar, vão ao Shopping, fazem exercícios físicos, leem livros de auto-ajuda eescutam música. Utilizam medicamentos de forma corriqueira ou sistemática. Semelhante a outros estudos sobre o burnout ${ }^{26}$, aqueles com menor tempo de formados tendem à desesperança. Os mais velhos sofrem, mas continuam esperando uma solução. Estariam mais complacentes? Extrairiam aspectos positivos de experiências negativas?

Essas atitudes favorecem ao desgaste que leva à percepção de que o trabalho na ESF tanto desencadeia 0 adoecimento, como agrava as doenças que já existiam. M ediante declarações espontâneas (forte indicativo de maior valorização) e respostas à pergunta feita pelo pesquisador, os médicos referem ansiedade, irritabilidade, falta de motivação, baixa satisfação no trabalho, depressão e frustração profissional, indicando 0 comprometimento da saúde mental. Eles são os profissionais que mais expressam o desejo de abandonar o trabalho. Também mencionam hipertensão arterial, cefaleia, enxaqueca, fadiga, 
dores musculares, insônia, dores articulares, tendinite, infecções recorrentes na orofaringe, gripes frequentes e distúrbios gastrintestinais:

[...] a coluna eu já sofria quando entrei no PSF, a hi pertensão adquiri lá - várias pessoas da equipe estão hipertensas - é esse PSF que estressa a gente demais, o estresse é muito grande... é estresse em cima de estresse, é cobrança em cima de cobrança, ébriga... eu adoeci ea equipe não entendia porque eu comecei a faltar muito na época, eu vivia com diarreias frequentes, com dores, enjoos, adoecendo muito, foi quando eu fui pra o cardiologista e ele entrou com antidepressivo. (M édica2 - 42 anos, 15 anos de formada, 7 anos na ESF e 4 anos e 9 meses na equipe atual).

Para esses profissionais, o trabalho se ressente do absenteísmo, da rotatividade e do desgaste. A pós se integrarem à ESF no Recife, 11 dos entrevistados já trocaram de equipe e um deles rescindiu o contrato. A enorme dificuldade para fixar-sena equipe tem feito a instituição oferecer salários diferenciados aos médicos. Eles justificam a rotatividade pelas difíceis relações na equipe, os problemas de acesso ao local de trabalho e a exposição à violência, mas alguns citam o desprestígio e a desvalorização social da autoridade técnica do médico. Este entrevistado revela seu desencanto:

No PSF eu não encontro a figura do médico que eu achava, é uma figura de um médico desvalorizada, éuma figura de um médico muito, sei lá, rabugenta, uma coisa que, não é bem o que eu gosto, eu não pretendo continuar no PSF não, tem que ter assim, muita vocação, e muita preparação na faculdade pra isso, a gentenão é preparado pra isso não, na faculdade. (M édico18 - 29 anos, 2 anos de formado, 2 anos na ESF e 8 meses na equipeatual).

Sobretudo entre as equipes consideradas com menos conflitos internos, classificadas como tendo uma situação boa, observa-se desacordo entre a percepção do Distrito e a expressa por seus membros. Os conflitos dentro da equipe passíveis de serem conduzidos com discrição, apesar de revestidos de gravidade, podem não ser percebidos em sua verdadeira magnitude pelos D istritos. Contudo, embora praticamente todos os médicossedigam desgastadoseinsatisfeitos, aqueles que compartilham algumas das dificuldades do trabal ho com a equipe, mostram-se mais propensos a "ir levando" o queacreditam ser difícil de transformar na ESF. São diferentes as repercussões do equilíbrio instável entre prazer e sofrimento: frequentemente os médicos valorizam os efeitos negativos do trabal ho, mas al guns, apesar de tudo, identificam os seus efeitos positivos no bem-estar pessoal. Poucos percebem uma melhora na sua qualidade de vida após a inserção na ESF, mesmo considerando o trabal ho desgastante e/ou existindo conflitos entre as exigências do trabalho e da família. N essas circunstâncias, sentem-se úteis, especialmente os aposentados, ou aliviados por terem se libertado dos plantões. Aspecto bastante positivo das vivências na ESF é que, apesar das difíceis relações com o trabalho, existe uma percepção generalizada do próprio trabalho como útil à população.

\section{Considerações finais}

M ais uma vez, a emergência de novas necessidades e significados no campo de atuação médica questiona a contradição entre inovação e sedimentação, subjacente ao processo identitário. As ambiguidades e conflitos decorrentes do desejo de mudanças e da resistência à flexibilização dos limites das competências técnicas têm efeitosnegativos sobre as vivências no trabal ho. Os participantes desta pesquisa experimentam um amplo conjunto de elementos dos contextos de trabalho que favorecem o desenvolvimento simultâneo de ineficácia profissional e desgaste continuado. Eles referem queixas relacionadas à saúde física, mental eà qualidade do trabalho.

A trajetória de vida profissional e as aspirações pessoais são aspectos importantes na passagem da singularidade de diferentes maneiras de existir por um só emesmo quadro de referência, que origina a identidade profissional ${ }^{4}$. Contudo, o desgaste crônico e a falta de realização profissional decorrem, principalmente, das situações onde a mudança de racionalidade do trabalho aumenta a complexidade e o desafio, sem que esteja presente o suporte organizacional necessário para realizá-lo a contento ${ }^{27}$. 0 distanciamento ea vontade de desistir que, de modo mais ou menos intermitente, encontram-se presentes no cotidiano de uma grande parte desses médiCOS, são estratégias de enfrentamento nocivas para a saúde do profissional e para a qualidade da atenção prestada à população 28 .

É necessário identificar caminhos para modificar essa realidade. Peduzzi ${ }^{25}$ destaca o caráter processual e complexo da divisão do trabalho, argumentando quea integração das ações depende de conexões percebidas e introduzidas ativa e conscientemente pelos membros da equipe. A atuação conscienterequer a construção deum projeto comum fundado na interdisciplinaridade do 
conhecimento e no caráter multiprofissional da operação do trabalho. Na promoção da saúde daqueles que trabalham é na aprendizagem da convivência na organização, ecom ela, que se encontra a chave para aumentar a qualidade do trabalho sem diminuir a qualidade de vida.

A força esclarecedora da reflexão e da autoreflexão eo andamento de uma discussão baseada no diálogo ena argumentação conferem legitimidade às sucessivas correções do percurso no mundo do trabalho, permitindo encontrar respostas sobre o quê, o como e o por quê devemos fazer algo. Quando está em jogo a tomada de posição diante de pretensões de val idade controversas sobre a melhor forma de atuar, cabe refletir com Habermas ${ }^{29}$ sobre a essencialidade das razões à luz das quais todos os parti cipantes podem descobrir juntos, dado um assunto que precisa ser regulamentado, qual a prática que podeatender ao interesse de todos (p. 14).

\section{Colaboradores}

KVO Feliciano, MH Kovacs eSW Sarinho participaram igualmente de todas as etapas de elaboração do artigo.

\section{Agradecimentos}

Aos médicos que compartilharam as suas percepções do cotidiano do trabalho. Ao Conselho Nacional de Desenvolvimento Científico e Tecnológico (CN Pq - Processo no403149/2004-5) e à O rganização Pan-Americana de Saúde (OPAS - Carta Acordo BR/LOA/0500107.001), pelo apoio financeiro. 
Referências

1. Schraiber LB. O médico e seu trabalho: limites da liberdade. São Paulo: Hucitec; 1993.

2. Dalmaso ASW. Análise de transformações da técnica em M edicina: reflexões sobre uma proposta metodológica. Interface - Comunicação, Saúde e Educação 2000; 4(6):49-60.

3. Brasil. M inistério da Saúde. Secretaria de Políticas de Saúde, Departamento de Atenção Básica. A implantação da unidade de saúde da família. Brasília: Cadernos de Atenção Básica, Programa de Saúde da Família; 2000. (Caderno 1).

4. Batista AS, Codo W. Crise de identidade e sofrimento. In: Codo W, organizador. Educação: carinho e trabalho. 2a ed. Petrópolis: Vozes; 2000. p. 60-85.

5. Ciampa AC. Identidade. In: Lane STM, Codo W, organizadores. Psicologia social: o homem em movimento. São Paulo: Brasiliense; 1984. p. 58-75.

6. Ricoeur P. 0 si-mesmo como um outro. Campinas: Papirus; 1991.

7. Gariglio MT, Radicchi ALA. O médico e seu processo de trabalho em serviços públicos de saúde: a descrição de um problema. Cien Saude Colet [periódico na internet] 2006 nov. [acessado 2007 jan 25]; Disponível em: http://www.cienciaesaudecoletiva. com.br

8. Horwitz N. El cambio de la práctica médica. Desafíos psicosociales para la profesión. Revista M édica Chile 2004; 132(6):768-772.

9. Codo W, Vasques-M enezes I. O que é burnout? In: Codo W. organizador. Educação: carinho e trabalho. 2a ed. Petrópolis: Vozes; 2000. p. 237-254.

10. Tamayo MR, Tróccoli BT. Burnout no trabalho. In: Mendes AM, Borges LO, Ferreira MC, organizadores. Trabalho em transição, saúde em risco. Brasília: Editora Universidade de Brasília; 2002. p. 45-63.

11. Sobrequés J, Cebriá J, Segura J, Rodriguez C, García $\mathrm{M}$, Juncosa $\mathrm{S}$. La satisfacción laboral y el desgaste profesional en los médicos de atención primaria. Atención Primaria 2003; 31(4):227-233.

12. Ruiz CO, Rios FL. El burnout o síndrome de estar quemado en los profesionales sanitarios: revisión y perspectivas. International Journal Health Psychology 2004; 4(1):137-160.

13. Tamayo MR, Tróccoli BT. Exaustão emocional: relações com a percepção de suporte organizacional e com as estratégias de coping no trabalho. Estudos de Psicologia 2002; 7(1):37-46.

14. Oliveira PR, Tristão RM, Neiva ER. Burnout e suporte organizacional em profissionais de UTI-Neonatal. Educação Profissional: Ciência e Tecnologia 2006; 1(1):27-37.

15. Paz M GT, Tamayo A. Perfil cultural das organizações. In: Tamayo A, organizador. Cultura e saúde nas organizações. Porto Alegre: Artmed; 2004. p. 19-38.
16. Farber BA. Crisis in education: stress and burnout in the American teachers. San Francisco (USA): Jossey-Bass Publishers; 1991.

17. Habermas J. Dialética e hermenêutica. Porto Alegre: L\&PM ; 1987.

18. Gadamer HG. Verdade e método: traços fundamentais de uma hermenêutica filosófica. 2a edição. Petrópolis: Vozes; 1998.

19. Minayo MCS. 0 desafio do conhecimento: pesquisa qualitativa em saúde. 9a ed. São Paulo: H ucitec; 2006.

20. Stotz EN. Enfoques sobre educação e saúde. In: Valla VV, Stotz, EM, organizadores. Participação popular, educação e saúde: teoria e prática. Rio de Janeiro: Relume-Dumará; 1993. p. 11-22.

21. Borges LO, Argolo JCT, Pereira ALS, M achado EAP, Silva WS. A síndrome de burnout e os valores organizacionais: um estudo comparativo em hospitais universitários. Psicologia: Reflexão e Crítica 2002; 15(1):189-200.

22. Borges LO, Argolo JCT, Baker M CS. Os valores organizacionais e a síndrome do burnout: dois momentos em uma maternidade pública. Psicologia: Reflexão e Crítica 2006; 19(1):34-43.

23. Onocko Campos R. 0 encontro trabalhador-usuário na atenção à saúde: uma contribuição da narrativa psicanalítica ao tema do sujeito na saúde cole tiva. Cien Saude Colet 2005; 10(3):573-583.

24. Meneses e Rocha AAM, Trad LAB. A trajetória profissional de cinco médicos do Programa Saúde da Família: os desafios de construção de uma nova prática. Interface - Comunicação, Saúde e Educação 2005; 9(17):103-116.

25. Peduzzi M. Mudanças tecnológicas e seu impacto no processo de trabalho em saúde. Trabalho, Educação e Saúde 2002; 1(1):75-91.

26. Feliciano KVO, Kovacs MH, Sarinho SW. Sentimentos de profissionais dos serviços de pronto-socorro pediátricos: reflexões sobre o burnout. Revista Brasileira de Saúde M aterno Infantil 2005; 5(3):319-328.

27. Soratto L, Pinto RM. Burnout e carga mental no trabaIho. In: Codo W, organizador. Educação: carinho e trabalho. 2ª ed. Petrópolis: Vozes; 2000. p. 282-292.

28. Antoniazzi AS, Dell'Aglio DD, Bandeira DR. 0 conceito de coping: uma revisão teórica. Estudos de Psicologia 1998; 3(2):273-294.

29. Habermas J. A ética da discussão e a questão da verdade. São Paulo: Martins Fontes; 2004.

Artigo apresentado em 17/07/2008

Aprovado em 15/03/2009

Versão final aprovada em 08/04/2009 